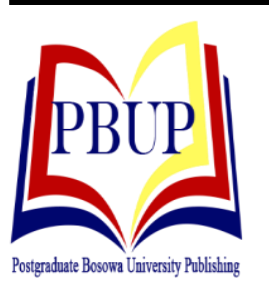

Postgraduate Bosowa University Publishing (PBUP)

Indonesian Journal of Business and Management e-ISSN: $2460-3767 \quad p-I S S N: 2656-6885$

https://postgraduate.universitasbosowa.ac.id/index.php/jbm

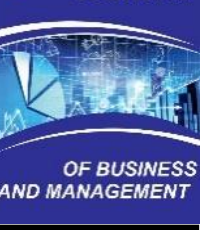

\title{
PENGARUH MOTIVASI INTRINSIK, MOTIVASI EKSTRINSIK DAN BUDAYA ORGANISASI TERHADAP KINERJA KARYAWAN PADA HOTEL AYANA KOMODO RESORT, WAECICU BEACH LABUAN BAJO NUSA TENGGARA TIMUR
}

\author{
The Influence of Intrinsic Motivation, Extrinsic Motivation, and Organization Culture on Employee \\ Performance in Hotel Ayana Komodo Resort, Waecicu Beach, Labuan Bajo, East Nusa Tenggara \\ Irawati A. Latif ${ }^{1}$, Herminawati Abubakar ${ }^{2}$, Miah Said ${ }^{2}$ \\ ${ }^{1}$ Human Resource Manager, Hotel Ayana Komodo Resort Kota Labuan Bajo \\ ${ }^{2}$ Program Studi Manajemen Program Pascasarjana Universitas Bosowa \\ Email: riandiandi915@gmail.com
}

Diterima: 10 Januari 2021/Disetujui: 02 Juni 2021

\begin{abstract}
ABSTRAK
Penelitian ini bertujuan untuk menganalisis pengaruh motivasi intrinsik dan motivasi ekstrinsik terhadap perilaku kinerja karyawan Hotel Ayana Komodo Resort Weicicu Beach serta menganalisis pengaruh Budaya organisasi terhadap kinerja karyawan Hotel Ayana Komodo Resort Weicicu Beach. Adapun metode penelitian yakni penelitian asosiatif kausal dengan menggunakan pendekatan kuantitatif. Teknik pengumpulan data dilakukan dengan teknik observasi, wawancara, kusioner, dan dokumentasi. Berdasarkan hasil penelitian ditemukan bahwa Berdasarkan nilai signifikansi dari tabel coefients diperoleh nilai signifikansi X1 sebesar $0.122 \leq 0.05$, nilai signifikansi X2 sebesar $0.099 \leq 0.05$ dan nilai signifikansi X3 sebesar $0.063 \leq 0.05$ sehingga dapat disimpulkan bahwa variabel X (motivasi kestrinsi, motivasi intrinsic dan budaya organisasi) berpengaruh terhadap variabel Y (kinerja).
\end{abstract}

Kata Kunci: Motivasi, Kinerja Karyawan, Ayana Komodo Resort Weicicu Beach

\section{ABSTRACT}

This study aims to analyze the effect of intrinsic motivation and extrinsic motivation on employee performance behavior at Hotel Ayana Komodo Resort Waecicu Beach and to analyze the influence of organization culture on employee performance at Hotel Ayana Komodo Resort Weicicu Beach. The research method is causal associative research using a quantitative approach. The data is collected by using observation, interview, questionnaire, and documentation. The results show that, based on the significance value of the coefficients table, X1 significance value was $0.122 \leq 0.05$, the X2 significance value was $0.099 \leq 0.05$ and the X3 significance value was $0.063 \leq 0.05$ so it could be concluded that the variable X (provincial motivation, intrinsic motivation and organizational culture) affects the variable $Y$ (performance).

Keywords: Motivation, Employee Performance, Ayana Komodo Resort Waecicu Beach

\section{PENDAHULUAN}

Sumber daya manusia merupakan aset penting yang dimiliki oleh perusahaan karena sumber daya manusia adalah satu-satunya aset organisasi yang dapat menggerakkan sumber daya lain (Henry Simamora, 2006). Untuk menggerakkan sumber daya dalam perusahaan yang ada secara efektif dan efisien memerlukan karyawan yang berkualitas. manajemen SDM sebagai unit bagian dari fungsi manajemen perusahaan harus memiliki strategi yang tepat dalam sistem pengelolaan karyawan seperti meningkatkan kinerja karyawan. Jika kinerja karyawan meningkat maka kinerja perusahaan juga akan meningkat sehingga memudahkan perusahaan dalam mencapai tujuannya.Begitu pentingnya peran sumber daya manusia untuk menentukan keberhasilan suatu perusahaan, sehingga organisasi harus mampu mewujudkan keinginan dan kebutuhan karyawan dengan motivasi guna mencapai kinerja yang tinggi. Setiap manajer harus memprediksi upaya untuk mengembangkan keterampilan dan 
kemampuan manajerial untuk memotivasi bawahan mereka. Manajer memiliki tanggung jawab untuk membantu dan mempengaruhi tindakan bawahannya agar dapat melaksanakan tugasnya secara efektif dan efisien.

Jadi keberhasilan seorang manajer dalam memotivasi bawahannya bergantung pada bagaimana manajer tersebut memahami motif para karyawannya. Dalam hal ini perusahaan tidak hanya mengharapkan karyawan yang mampu, trampil, dan trampil, tetapi yang terpenting ingin bekerja keras dan ingin mencapai hasil kinerja yang maksimal (Hasibuan, 2007). Karyawan yang memiliki motivasi tinggi untuk menempati posisi yang lebih tinggi dalam organisasi dapat meningkatkan produktivitas kerja untuk mencapai tujuan organisasi dan sebaliknya. Dengan memahami peran yang dimainkan oleh motivasi, manajer akan mampu meningkatkan produktivitas kerja bawahannya dan meningkatkan kinerja.Siagian (2007) menyatakan bahwa dengan motivasi yang tepat karyawan akan termotivasi untuk melakukan yang terbaik dalam melaksanakan tugasnya karena percaya bahwa dengan keberhasilan organisasi dapat mencapai tujuan dan tujuannya, maka kepentingan pribadi anggota organisasi juga akan dilindungi. keduanya diutamakan dan dapat diterima dengan baik oleh karyawan, karena motivasi tidak dapat diberikan kepada setiap karyawan dalam bentuk apapun. Dengan memotivasi karyawan, karyawan merasa bertanggung jawab atas pekerjaannya dan berkontribusi pada hotel yang mereka gunakan, yaitu menjalankan tugas dan tanggung jawabnya. Motivasi internal adalah bagian dalam memilih karyawan untuk bekerja berdasarkan kemauannya untuk bekerja, bekerja karena tanggung jawab untuk memenuhi kebutuhan keluarga, pengakuan dan penghargaan dari orang lain atas pekerjaan yang dimilikinya. Sedangkan motivasi eksternal berkaitan dengan apa yang diberikan hotel kepada karyawan setelah karyawan melaksanakan tugasnya agar karyawan mendapatkan hak. Motivasi eksternal termasuk gaji, tunjangan, hadiah dan bonus, dan penghargaan lainnya.

Salah satu hotel yang terus berupaya meningkatkan kinerjanya adalah Hotel Ayana Komodo Resort yang telah berdiri sejak tahun 1996 dan merupakan hotel bintang lima satu-satunya di Labuan Bajo. Hotel ini terus berbenah diri oleh karena adanya persaingan antara sesama hotel baik bintang 3 maupun bintang 4 di Labuan Bajo. Adapun perhatian utama Hotel Ayana Komodo Resort adalah dengan memperhatikan kinerja karyawannya. Hal ini penting karena kinerja Hotel Ayana Komodo Resort sangat ditentukan oleh kinerja karyawannya. Kinerja perusahaan menentukan apakah perusahaan itu akan berhasil atau tidak dalam persaingan bisnis. Sebagaimana dijelaskan oleh Armstrong dan Baron dalam Wibowo (2007), kinerja merupakan hasil kerja yang mempunyai korelasi kuat dengan tujuan strategis organisasi, kepuasan pelanggan, dan kontribusi ekonomi. Untuk mencapai kinerja yang tinggi, perusahaan atau organisasi harus mampu mendayagunakan berbagai sumber daya seperti modal, material, dan mesin. Tidak hanya terbatas pada hal-hal tersebut, tetapi yang lebih penting adalah bagaimana perusahaan mempersiapkan sumber daya manusia yaitu karyawannya. Karyawan merupakan sumber daya penting bagi perusahaan karena karyawan memiliki bakat, energi, dan kreativitas untuk mendukung target perusahaan yang telah ditetapkan.

Kinerja pegawai sangat erat kaitannya dengan penilaian kinerja, oleh karena itu penilaian kinerja pegawai harus dilakukan oleh organisasi atau pegawai. Keberhasilan pemimpin dalam menerapkan kepemimpinan yang optimal dan motivasi kerja yang tinggi akan menghasilkan kinerja untuk mencapai tujuan perusahaan. Pertunjukan adalah tindakan, bukan acara. Kinerja kinerjanya sendiri mencakup banyak komponen dan bukan hasil yang instan. Kinerja bersifat individual karena setiap karyawan memiliki tingkat kemampuan yang berbeda dalam melaksanakan suatu tugas. Kinerja tergantung pada kombinasi kemampuan, upaya, dan peluang yang diperoleh akan dan tidak akan dicapai oleh karakteristik kinerja individu.

Marwansyah (2010) menyatakan bahwa: "Sebagai pendayagunaan sumber daya manusia di dalam organisasi, yang dilakukan melalui fungsi-fungsi perencanaan sumber daya manusia, rekrutmen dan seleksi, pengembangan sumber daya manusia, perencanaan dan pengembangan karir, pemberian kompensasi dan kesejahteraan, keselamatan dan kesehatan kerja dan hubungan industrial".

Menurut Moorhead dan Griffin (2013), saat ini hampir semua praktisi dan sarjana memiliki definisi motivasi. Biasanya, kata-kata berikut termasuk dalam definisi: keinginan, keinginan, harapan, target, target, kebutuhan, dorongan, motivasi, dan insentif. Secara teknis, istilah motivasi berasal dari bahasa latin movere yang artinya "bergerak". Makna ini dibuktikan dengan definisi lengkap di bawah ini: Motivasi adalah proses yang dimulai dengan kekurangan fisiologis atau psikologis yang menghasilkan tindakan atau insentif yang ditujukan pada tujuan. Jadi, kunci untuk memahami proses motivasi bergantung pada pemahaman dan hubungan antara kebutuhan, dorongan, dan insentif.

Menurut Siagian (2004) motivasi intrinsik berasal dari dalam diri individu. Motivasi ini mempengaruhi integritas target, tujuan organisasi maupun target individu, yang keduanya dapat memuaskan. Menurut Manullang (2001) yang menyatakan bahwa suatu perusahaan tidak memberikan kondisi kerja, upah, tunjangan, atau keamanan yang memadai di tempat kerja, akan sulit untuk menarik karyawan yang baik dan perputaran serta absensi akan meningkat.

Menurut Mangkunegara (2009) kinerja adalah hasil kerja dengan kualitas dan kuantitas yang dicapai oleh karyawan untuk melaksanakan tugas setelah melaksanakan tanggung jawab yang diberikan, akan tetapi menurut Hadari (2001) apa yang disebut kinerja 
adalah hasil dari pelaksanaan tugas.

Organisasi atau perusahaan membutuhkan karyawan sebagai sumber dukungan utama untuk mencapai tujuan mereka. Sumber daya manusia yang berkualitas akan membantu meningkatkan organisasi sebagai wadah untuk meningkatkan produktivitas kerja.

\section{METODE}

Penelitian ini merupakan penelitian asosiatif kausal dengan menggunakan pendekatan kuantitatif. Penelitian asosiatif kausal adalah penelitian yang bertujuan untuk menguji pengaruh dari dua variabel atau lebih yaitu untuk mengetahui sebab akibat antara variabel bebas dan variabel terikat. Variabel bebas yang digunakan dalam penelitian ini adalah motivasi dan budaya organisasi. Variabel terikat yang digunakan dalam penelitian ini adalah kinerja pegawai.

Pendekatan kuantitatif adalah cara mengolah data untuk memperjelas situasi perusahaan kemudian dianalisis berdasarkan data yang tersedia.Kajian ini merupakan penelitian tentang hal-hal atau peristiwa yang terjadi tanpa adanya manipulasi variabel secara langsung dan tanpa menciptakan kondisi tertentu.

a) Lokasi penelitian ini dilakukan di hotel Ayana Komodo Resort Weicicu Beach Labuan Baju Kabupaten Manggarai Provinsi Nusa Tenggara Barat pada hilan Januari-Juli 2020. Teknik pengumpulan data dilakukan dengan observasi, kusioner, wawancara dan dokumentasi, Dalam penelitian ini, teknik yang digunakan adalah analisis regresi linier berganda dan menggunakan alat bantu berupa software SPSS (Statistical Package for Social Sciences) adalah sebuah program komputer yang digunakan untuk menganalisis sebuah data dengan analisis statistik, SPSS yang digunakan dalam penelitian ini adalah SPSS versi 20.

\section{HASIL DAN PEMBAHASAN}

Gambaran Hotel Ayana Komodo Resort Weicicu Beach Terkenal dengan keramahan kelas dunia, desain hotel yang mengagumkan dan standar layanan yang tak tertandingi di Bali dan Jakarta, Ayana adalah resort bintang lima yang pertama di Pantai Waecicu, Pulau Flores, hanya dengan satu jam penerbangan dari Pulau Bali yang sangat indah.

Ayana Komodo Resort, Waecicu Beach mulai beroperasi pada 15 September 2018. Resort ini memiliki 13 suites dan 192 kamar tamu premium yang terletak di pantai pasir putih Labuan Bajo. Terinspirasi dari konsep relaxed resort lifestyle Ayana, bangunan ini kemudian memiliki tempat tinggal yang berbaur langsung dengan alam. Setiap ruangan kontemporernya menyuguhkan pemandangan laut yang sempurna dengan jendela yang berukuran besar agar tamu resort dapat melihat matahari terbenam di belakang pulau Kukusan.

Terletak di salah satu pulau yang paling terkenal dan indah di Indonesia, tamu resort akan menikmati ragam pemandangan yang luar biasa di Komodo, pemandangan bawah lautnya, dan melihat binatang yang dilestarikan oleh UNESCO World Heritage di darat dan laut dengan guide berpengalaman.

Ayana Komodo Resort Weicicu Beach merupakan resort bintang lima pertama yang ada di Weicicu Beach Labuan Bajo. Lokasinya sangat strategis sebab hanya membutuhkan satu jam penerbangan dari pulau Bali. Kisaran tarif resmi menginap di Ayana Komodo Resort Weicicu Beach Rp. 3.200.000- Rp.7.700.000 permalamnya. Tariff ini belum termasuk pajak dan biaya tambahan lainnya.

Untuk menikmati pesona wisata bahari yang terdapat di Labuan Bajo Ayana Komodo Resort menawarkan paket wisata yang menarik, dengan kondisi alam Labuan Bajo yang mempesona dan pasir putihnya anak-anak dapat bermain dengan gembira, aman dan nyaman saat berenang. Selain itu untuk menikmati alam bawah laut Flores Ayana Komodo Resort menyediakan glass bottom boat, yakni kapal Lako Taka. Wisatawan dapat menikmati karang bawah laut dan ikan warna-warni dari atas kapal yang lantainya dari kaca. Selian itu pengunjung juga dapat melakukan aktivitas snorkeling, Berlatih yoga, berolahraga menaiki kano dan menikmati indahnya pink beach.

Namun bagi wisatawan yang ingin melihat komodo di habitat aslinya, Taman Nasional Komodo, kapal cepat Lako Cama siap mengantar ke sana. Sementara untuk wisatawan yang suka berpetualang dalam beberapa hari, Ayana menyediakan Lako Di'a, sebuah kapal phinisi yang dibuat khusus laksana hotel terapung dengan 9 kamar dilengkapi kamar mandi, shower, wastafel, dan toilet.

Pengujian hipotesis bertujuan untuk menguji hipotesis yang diajukan. Hipotesis yang diajukan dalam penelitian ini terkait variabel motivasi intrinsik, ekstrinsik dan budaya organisasi. Analisis regresi berganda dipilih untuk menganalisis pengajuan hipotesis dalam penelitian ini. Berikut ini hasil analisis regresi berganda yang dilakukan dengan menggunakan program SPSS 20.00 for Windows.

1. Motivasi Intrinsik Berpengaruh Positif Terhadap Kinerja Karyawan

Hasil pengujian pada tingkat kepercayaan 95\% dapat disimpulkan bahwa Motivasi Intrinsik berpengaruh terhadap Kinerja Karyawan. Dapat dikatakan bahwa penelitian ini memperkuat hasil penelitian dan teori yang dikemukakan oleh Natsir (2005), Paramita (2007), Robbins, (2008), Ryyan (2012), dan Kulsum (2008). Banyak penelitian telah dilakukan untuk mengetahui pengaruh motivasi intrinsik terhadap kepuasan kerja. Hasil penelitian Eka (2016), Stringer et al. (2011), Bahrulmazi et al. (2013) Budianto et al. (2013), dan Son (2013) menunjukkan bahwa terdapat pengaruh positif antara motivasi intrinsik terhadap kepuasan kerja. Berdasarkan penelitian di atas maka dapat disimpulkan hipotesis sebagai berikut. 
Dari hasil penelitian yang dilakukan oleh peneliti dapat diketahui bahwa terdapat keterkaitan antara motivasi ekstrinsik dengan kinerja pegawai yang diperkuat dengan hasil analisis regresi. Hasil uji regresi menunjukkan hasil yang signifikan pada variabel motivasi intrinsik untuk kinerja 0,312 lebih kecil dari toleransi kesalahan $\alpha \alpha=$ 0,05 . Pengaruh yang diberikan bersifat positif dan signifikan, artinya motivasi intrinsik yang diberikan oleh atasan karyawan menyebabkan hasil kerja saya meningkat. Hasil uji t diketahui memiliki nilai t sebesar 2,663 . Hasil penelitian ini menunjukkan bahwa motivasi intrinsik berpengaruh positif dan signifikan terhadap kinerja pegawai. Berdasarkan hasil penelitian uji hipotesis diketahui bahwa motivasi ekstrinsik berpengaruh positif dan signifikan terhadap kinerja. Artinya apabila motivasi intrinsik yang diberikan kepada karyawan baik karena memberikan kesempatan kepada karyawan untuk mencapai hasil, pengakuan, wirausaha, tanggung jawab, dan pengembangan, maka kinerja karyawan terhadap perusahaan akan semakin tinggi.

\section{Motivasi Ekstrinsik Berpengaruh Positif Terhadap} Kinerja Karyawan

Dari hasil penelitian yang dilakukan oleh peneliti dapat diketahui bahwa terdapat keterkaitan antara motivasi ekstrinsik dengan kinerja pegawai yang diperkuat dengan hasil analisis regresi. Hasil uji regresi menunjukkan hasil yang signifikan pada variabel motivasi ekstrinsik untuk kinerja 0,358 lebih kecil dari toleransi kesalahan $\alpha \alpha=$ 0,05 . Pengaruh yang diberikan bersifat positif dan signifikan, artinya motivasi ekstrinsik yang diberikan oleh pemberi kerja berdampak pada peningkatan hasil kerja. Hasil uji t diketahui nilai t hitung sebesar 2,483. Hasil penelitian ini menunjukkan bahwa motivasi ekstrinsik berpengaruh positif dan signifikan terhadap kinerja karyawan.

Penelitian ini menunjukkan bahwa motivasi ekstrinsik dapat mempengaruhi Kinerja Karyawan secara individu, tetapi tidak signifikan. Hal ini dapat dimaklumi karena adanya motivasi ekstrinsik dari luar diri pribadi. Motivasi bekerja juga dipengaruhi oleh motivasi intrinsik, yang tidak diteliti dalam penelitian ini. Misalnya jika seseorang tidak memiliki motivasi intrinsik yang kuat untuk bekerja, maka malas, tetapi jika mendapatkan motivasi ekstrinsik yang positif, motivasi intrinsik dapat diubah menjadi lebih baik.

3. Motivasi Budaya Organisasi Berpengaruh Positif Terhadap Kinerja Karyawan

Dari hasil penelitian yang dilakukan oleh peneliti dapat diketahui bahwa terdapat hubungan antara budaya organisasi dengan kinerja pegawai yang diperkuat dengan hasil analisis regresi. Hasil uji regresi pada tabel 4.19 menunjukkan hasil yang signifikan variabel budaya organisasi terhadap kinerja 0,308 lebih kecil dari $\alpha$ toleransi kesalahan $\alpha=0,05$. Pengaruh yang diberikan bersifat positif dan signifikan artinya budaya organisasi yang diterapkan pada karyawan dapat meningkatkan hasil kerja. Hasil uji $\mathrm{t}$ diketahui nilai $\mathrm{t}$ hitung sebesar 1,340. Hasil penelitian ini menunjukkan bahwa budaya organisasi berpengaruh positif dan signifikan terhadap kinerja pegawai.

Menurut Robbins dalam Tika (2010: 06) menegaskan bahwa budaya organisasi adalah sekumpulan 33 sistem nilai yang dikenali dan diciptakan oleh semua anggota yang berbeda-beda antara satu perusahaan dengan perusahaan lainnya. Dengan budaya organisasi yang terdefinisi dengan baik, karyawan akan dapat melaksanakan tugas tepat waktu dan membimbing karyawan untuk mencapai tujuan organisasi. Budaya organisasi juga diciptakan agar kelompok karyawan dapat menyelesaikan masalah eksternal dan internal, serta berfungsi sebagai kode etik bagi anggota saat menghadapi masalah.

\section{KESIMPULAN DAN SARAN}

Dapat dipahami bahwa terdapat hubungan antara motivasi intrinsik dengan kinerja karyawan yang diperkuat dari hasil analisis regresi. Yang menunjukkan hasil yang signifikan pada variabel motivasi intrinsik untuk kinerja. Pengaruh tersebut bersifat positif dan signifikan, artinya motivasi intrinsik yang diberikan oleh pemberi kerja mengakibatkan peningkatan hasil kerja pada uji hipotesis ditemukan bahwa motivasi ekstrinsik berpengaruh positif dan signifikan terhadap kinerja. Artinya apabila motivasi intrinsik diberikan kepada karyawan yang baik, seperti memberikan kesempatan kepada karyawan untuk mengupayakan hasil, pengakuan, wirausaha, tanggung jawab, dan pengembangan maka kinerja karyawan terhadap perusahaan akan semakin tinggi. Terdapat pula hubungan antara motivasi ekstrinsik dengan penguatan kinerja pegawai berdasarkan hasil analisis regresi yang menunjukkan hasil yang signifikan pada variabel kinerja motivasi ekstrinsik berpengaruh positif dan signifikan yang diterapkan oleh atasan pegawai yang menghasilkan hasil kerja. Hasil penelitian menunjukkan bahwa motivasi ekstrinsik dapat mempengaruhi kinerja karyawan secara individu tetapi tidak signifikan. Hal ini dapat dimaklumi karena adanya motivasi ekstrinsik dari luar individu. Motivasi bekerja juga dipengaruhi oleh motivasi intrinsik, yang tidak diteliti dalam penelitian ini. Misalnya jika ada orang yang tidak memiliki motivasi intrinsik yang kuat untuk bekerja, bekerja dengan malas, namun jika memiliki motivasi ekstrinsik yang positif maka motivasi intrinsik dapat diubah menjadi lebih baik. Dan untuk hubungan antara budaya organisasi dengan kinerja karyawan diperkuat dengan hasil analisis regresi. Hasil uji regresi menunjukkan hasil yang signifikan untuk variabel budaya organisasi terhadap kinerja. Pengaruh tersebut positif dan signifikan, artinya budaya organisasi yang 
dianut oleh karyawan mengakibatkan peningkatan hasil kerja. Hasil penelitian ini menunjukkan bahwa budaya organisasi berpengaruh positif dan signifikan terhadap kinerja pegawai.

\section{DAFTAR PUSTAKA}

Ghozali, Imam. 2005. Multivariate Analysis Application with SPSS. Semarang: Badan Penerbit UNDIP

Ghozali, Imam. 2011. Aplikasi Analisis Multivariate dengan Program IBM SPSS19. Edisi5. Semarang: Badan Penerbitan Universitas Diponegoro

Hadari, Nawawi, dan Mimi Martini. 2001. Penelitian Terapan. Yogyakarta: Gajah Mada University Press

Hasibuan, Malayu S.P.2007. Organisasi dan Motivasi: Dasar Peningkatan Produktifitas. Jakarta: Bumi Aksara

Hasnawati, H., Sapiri, M., \& Ruslan, M. (2021). Pengaruh Motivasi Dan Gaya Kepemimpinan Terhadap Kinerja Pegawai Pada Kantor Rumah Tahanan Negara Kelas Iib Selayar. Indonesian Journal of Business and Management, 2(2), 87-93.

Mangkunegara, A.P. 2009. Manajemen Sumber Daya Manusia Perusahaan Remaja Bandung: Rosdakarya

Manullang, M. 2001. Manajemen Sumber Daya Manusia. Yogyakarta: Andi Offset

Marwansyah. 2010. Manajemen Sumberdaya Manusia Edisi Dua. Bandung: Alfabeta

Moorhead dan Griffin. 2013. Perilaku Organisasi. Jakarta: Salemba Empat

Pabundu Tika.2010. Budaya Organisasi dan Peningkatan Kinerja Perusahaan, cetakan ke-3. Jakarta: PT. Bumi Aksara.

Robbins, Stephen P, dan Timothy A. Judge. 2008. Perilaku Organisasi Edisi Ke-12, Jakarta: Salemba Empat

Santoso, Singgih. 2012. Panduan Lengkap SPSS Versi 20. Jakarta: PT Elex Media Komputindo.

Siagian, Sondang P. 2004. Teori Motivasi dan Aplikasinya. Jakarta: Rineka Cipta

Siagian, Sondang P. 2007. Manajemen Sumber Daya Manusia. Edisi 1. Cetakan 14. Jakarta: Bumi Aksara

Simamora, Henry. 2006. Manajemen Sumberdaya Manusia. Yogyakarta: Sekolah Tinggi Ilmu Ekonomi YKPN.

Wibowo, 2007. Manajemen Kinerja. Jakarta: PT Raja Grafindo Persada 